\title{
Fat Grafting Techniques and Outcome in Scar Face
}

A.Y.Farid, G.I.ELhabaa, A.M.Abdelmofeed, M.E.AbdElattif and W.M.Habib

General \& plastic surgeries Dept., Faculty of Medicine, Benha Univ., Benha, Egypt

E-Mail:Waleed236@gmail.com

\begin{abstract}
Control of facial scarring is one of the most difficult challenges in surgical practice, and represents a difficult therapeutic problem facing plastic surgeons to achieve good results. To date, no gold standard exists for the treatment of scar tissue. Autologous fat grafting has been introduced as a promising treatment option for scar tissue related symptomsHowever, those experimental confirmation for its viability remains vague. With assess techniques, results of fat grafting Also its effects once enhancing the facial scars. This study might have been directed for 20 patients for clear facial scars. Patients' agdistis went starting with 8 to 60 A long time. Patients were chosen haphazardly will a chance to be dealt with for fat grafting. The abdomen might have been those practically usually decided contributor site. Fat might have been transformed with axis done 10 (group An) and natural in the different 10 cases (group b (. Fat grafting demonstrated should bring a critical part clinched alongside scar remodeling. This might have been measured clinically Toward those vancouver scar scale. In regards to tolerant fulfillment for cosmea appearance, 9 situations were assessed as excellent, 6 cases were assessed Likewise good, and 3 situations were assessed Similarly as reasonable Furthermore 2 were assessed Concerning illustration terrible. Autologous fat grafting need An critical part for facial scar remodeling Also gives An useful impact for facial scar tissue. Noteworthy change over scar appearance, skin characteristics, Also rebuilding of volume and three-dimensional shape will be accounted. There may be no noteworthy Contrast between comes about from claiming both bunches.
\end{abstract}

Keywords: Fat Grafting; Scar Face; plastic surgeries.

\section{Introduction}

If created by injury, surgery or burn, scar could a chance to be disfiguring. Scars emerge against whatever remains of those skin a result scar tissue may be committed for collagen phones as opposed Common skin units [1].

As An result, scars would as a rule an alternate color, Also don't need sweat organs alternately hair follicles. Those seriousness of a scar relies with respect to huge numbers factors, including the extent Also profundity of the wound, the blood supply of the area, those thickness and the shade of the skin. Exactly individuals particularly the individuals with deeper skin wound have a inclination to keloid arrangement [2].

Scars camwood negatively influence self confidenceor remind patients for traumatic mischance. They might a chance to be a point of convergence of unkind consideration also. They could tingle or harm (in instance from claiming A large number keloid scar) alternately Actually limit action. Same time scar amendment can't make An scar vanish completely, scar amendment technique might decrease the manifestation for scars, Also assistance restore a harmed self- picture. Frequently the system could Significantly move forward the work of the webpage dealt with Eventually Tom's perusing moving those firmness of the skin [3].

Control from claiming scarring is absolutely a standout amongst those The greater part was troublesome tests about surgical practice, displays a troublesome restorative issue Furthermore The greater part surgeons need looked for should accomplish the mossycup oak tasteful scars. An main consideration figuring out the last cosmea manifestation for cutaneous (facial) scar may be pressure acting on the wound edges Throughout the recuperating stage. Since those oder Kocher Pioneered the arrangement of skin incisions with Langer's Lines clinched alongside 1892, surgical systems that endeavor with beat shutting strain have get to be standard yet; no medication need been accessible with minimize underlying muscle contractions, which need aid the significant reason for this strain [4].

Medicine of facial scars camwood make testing proposition Actually for the encountered medical practitioners. Various medications exist that the doctor might utilization will treat those tolerant. In light of every about these strategies could incompletely enhance the scar in An specific way, a consolidation of medicines will be every now and again required should accomplish maximal effects. Patients camwood need implausible desire regarding the determination from claiming their lesions, and the doctor must Along these lines committee the tolerant once which kind about upgrades might make seen. One must also accentuate that complete determination of the scar might not a chance to be possible, and the different medicines (of you quit offering on that one or changing procedures) every now and again are needed. Scars on the face also every now and again convey a greater amount mental effect for the patient, and these issues have with a chance to be tended to. Hence, additional Forethought ought to make made At treating facial scars. Large portions of the investigations with respect to scars need aid done once different parts of the figure. Precautions ought be taken when taking this data What's more 
extrapolating it for use on the face. Facial skin may be thinner, especially in the orbital zone. Skin likewise need that's only the tip of the iceberg appendages, including hair follicles, which ought to a chance to be thought seriously about for those distinctive medicines [5].

Scars could Additionally actuate unending pain, which might create then afterward intense pain, a side effect of typical wound recuperating. Another manifestation is itchiness, handling extreme uneasiness Furthermore making patients to scratch, which thus threatens the recuperating transform. Furthermore, hypertrophic alternately keloid scars, contractures, and bond arrangement could cause practical constraints [6].

It will be vital to assess the kind of scar on the introductory interview. Diverse scars react to different modalities about medicine for changing degrees for triumph. In the beginning consultation, the physical aspects of the scar that make it unique in relation to those encompassing skin if a chance to be identifier. For the vast majority scars, a few viewpoints requirement will make addressed, conceivably in distinctive approaches. Will be the scar raised alternately depressed? Actually a onemm Contrast camwood cast An shadow on the face that might aggravate An scar a greater amount evident. [5].

Current medication choices for facial scars incorporate topical anesthesia alternately intralesional corticosteroid injections, intralesionalbleomycin or 5-fluorouracil, silicone gel sheets, weight therapy, radiotherapy, cryotherapy, laser, Also surgery. Other methodologies including the utilization from claiming collagen union inhibitors, nonsteroidal mitigating agents, minocycline, angiotensinconverting catalyst inhibitors, What's more gene treatment are at present under study. These systems change over efficacy, What's more their use is restricted Toward secondary repeat rates Furthermore side-effects including pigmentary changes, skin atrophy, and torment. In spite of those improvemen of cosmea lasers and other lightbased units need permitted those successful medicine from claiming a significant number cosmea issue that were formerly not treatable, the undesired difficulties would an actuality for their clinical provision [7].

In spite of clinicians Furthermore analysts have portrayed an assortment about conventions for the medicine from claiming scar tissue, restricted information over the viability would determined starting with well-designed, prospective, randomized controlled clinical trials. To date, no gold standard exists to those medicine of scar tissue. Medicines are mostaccioli In light of the unique knowledge from claiming clinicians, for changing degrees of victory [8].
An generally new alternative to the medicine about scar tissue will be the utilization for autologous fat grafting, primary portrayed Toward Neuber On 1893 What's more later refined Toward Coleman. Autologous fat grafting need An volumeincreasing impact Furthermore may be thought will animate the neosynthesis of collagen fibers, which In increments dermal thickness, bringing about a change to skin personal satisfaction. It need additionally demonstrated change in distinctive sorts for ache. The theory is that mesenchymal phones of the graft furnish prolonged absense of pain by transforms in the microenvironment What's more emission about substances. The utilization from claiming autologous fat grafting need expanded On as a relatable point practice, Yet to date there will be an absence of experimental proof in regards those impacts with respect to scar tissue [9].

The point from claiming this investigation might have been will assess techniques, results for fat grafting Furthermore its comes about once moving forward the facial scars.

\section{Patient and methods}

This ponder might have been conveyed out during plastic surgery division for Benha school healing facility starting with january 2019 with december 2019. This study incorporated 20 patients with upsetting, self-evident facial scars from claiming different etiological variables.

Patients were completely educated something like the system, Also composed agrees were got from every last bit patients. Those ages about patients differed the middle of 8-60 A long time.

\section{Inclusion criteria}

All patients with facial scars of different etiological factors (post - traumatic ,post -burn , and post inflammatory scars) were eligible .

\section{Exclusion criteria}

Patients with sever chronic illness, mentally or psychologically disoriented, pregnant women, presence of active infection, contracted scars and keloid or hypertrophic scares, all above cases were excluded from the study .

We use a ramdomized pattern in classifying patients into two groups :

Group A :(fat processing) Fig (1).

The aspirated fat was transferred to $10-\mathrm{ml}$ syringes and then centrifuged at $3000 \mathrm{rpm}$ for $3 \mathrm{~min}$ using 80-1 Electric centrifuge (Jiangsu jinyi instrument techrology company limited Jiangsu , china) . to concertate fat particles, and separate them from fluids and debris, which were then discarded . 

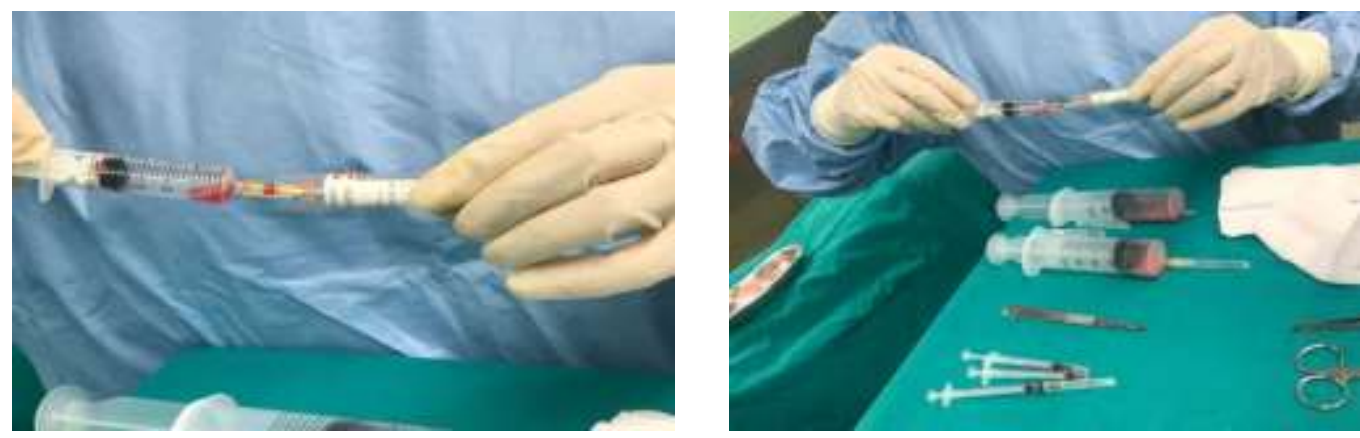

Fig (1)

\section{Group B :( non - processed fat ) Fig ( 2 \& 3)}

The aspirated fat was transferred to $10-\mathrm{ml}$ syringes and simply left to stand by gravity for 30 minutes. The fat was separated from fluids which was discarded. From both groups the purified fat was the transferred to 1-ml suringes that was ready for injection .
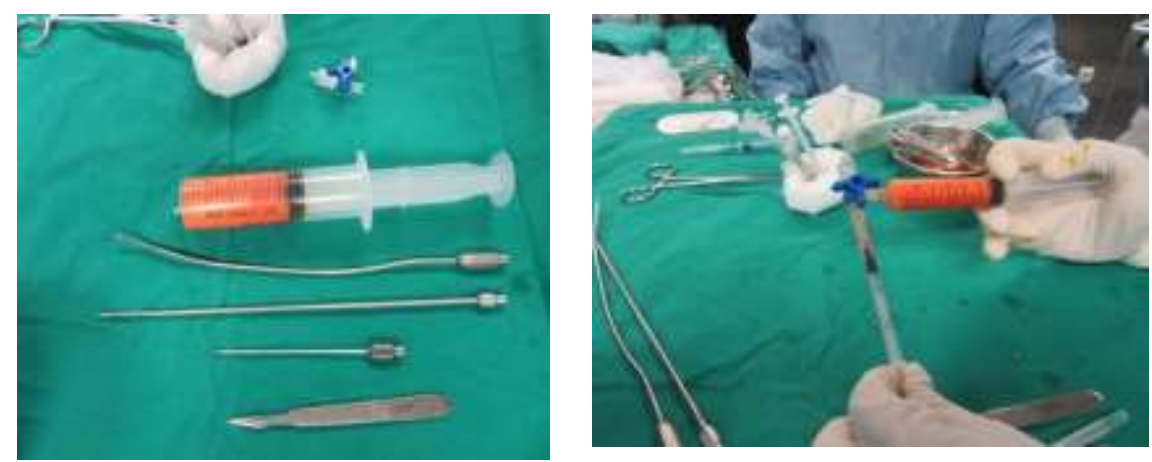

$\operatorname{Fig}(2)$
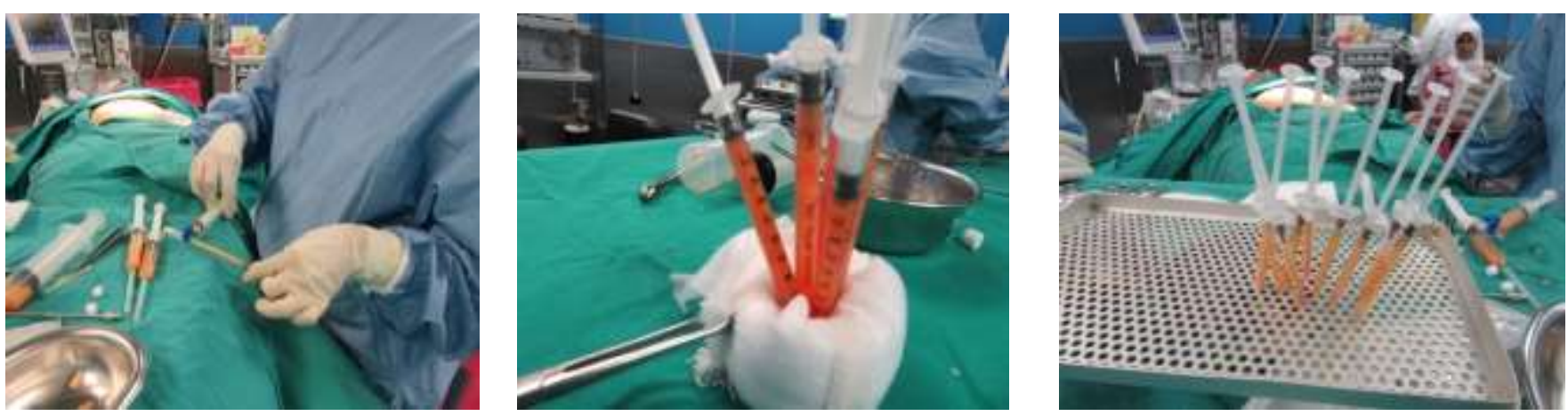

Fig (3)

Fat injection :a 1-ml syringes with a 2-mm fat- injection blunt cannula attached to its nozzle was used . Through a small skin incision the cannula was used to release the adhernce of the scar in all planes and create a subcutaneous tunnels in a fan-shared manner into which the fat cells were deposited when the cannula withdrawn . The amount of fat grafted depended on extension of scar that needed treatmentover correction of about $20 \%$ was performed contour irregularities were minimized using digital pressure after injection Fig (4). 

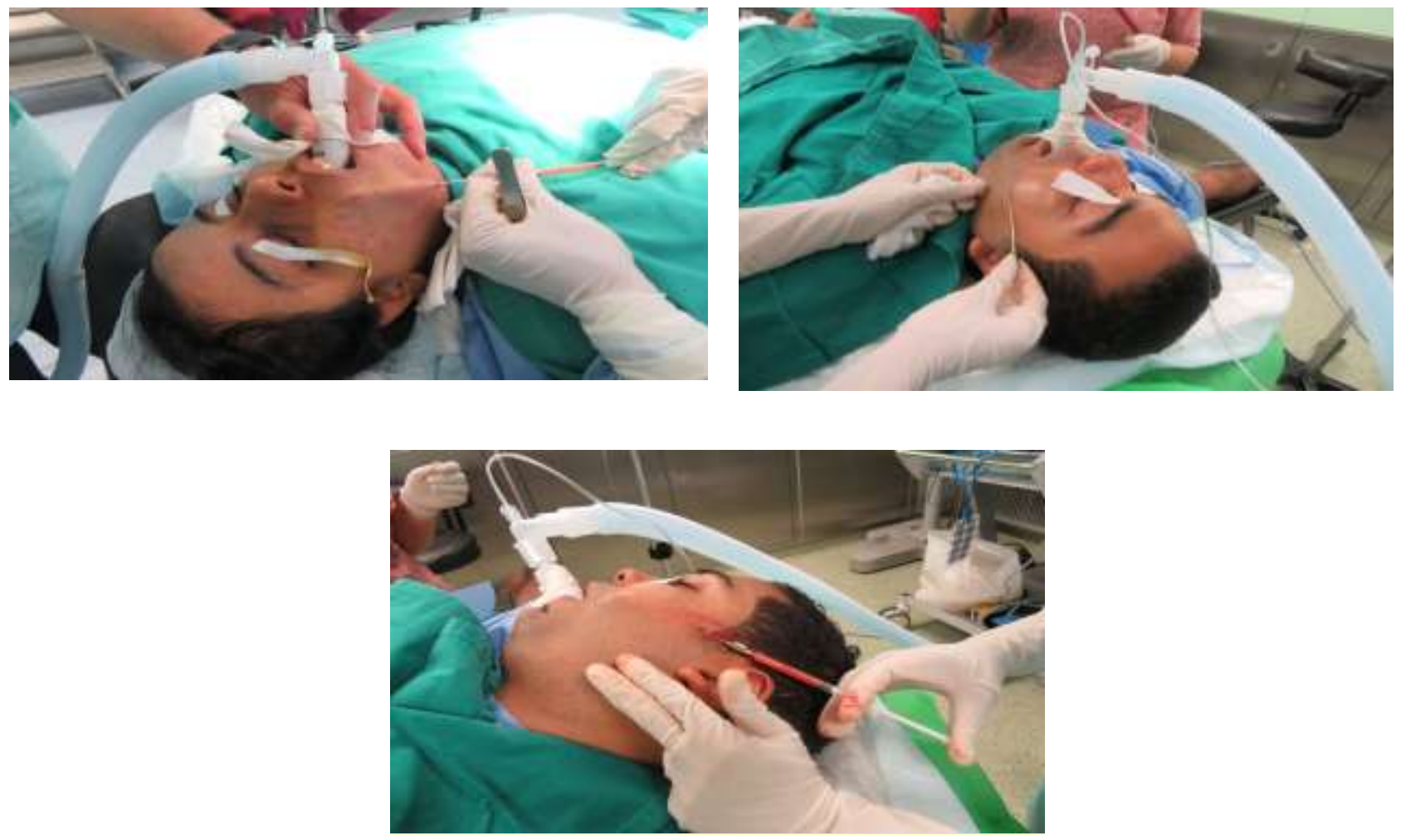

Fig (4)

\section{Postoperative care}

All patients received antibiotics and analgesics

\section{Follow- up and assessment}

Results were assessed by clinical examination and postoperative photographs obtained 5 days and 2 weeks postoperatively and then at 1,3 , and 6 months postoperatively. The postoperative outcome was evaluated according to the esthetic appearance of the scar, patient satisfaction with regard to overall improvement of scars, and complications of the procedure. Therapeutic response was determined according to the scores on the Vancouver Scar Scale (VSS) and patient self assessment scale [10].

\section{Results}

The introduce study found An noteworthy change On tolerant fulfillment after infusion (79\%) in examination with those preinjection state, Also this may be a great pointer of the impact from claiming fat infusion for respect to An huge transform in the scar.

Both gathering from claiming fat infusion $(A \& B)$ in this consider indicated no critical Contrast between them Similarly as see the scar result and we Think as of the outcomes Concerning illustration person assembly.
In regards those VSS, there might have been noteworthy change over vascularity Furthermore pliability about scars for change for scar pigmentation. There might have been also decrease in the level for torment Also tingling Similarly as evaluated Toward the self appraisal score in regards the level for pruritus, as evaluated Eventually Tom's perusing those self evaluation score, those tolerant might have been required to verbally show the level for pruritus, which might have been spoken to Similarly as none, mild, moderate, or severe, and numbered $0-3$. In regards the level from claiming agony Likewise assessed Toward those self evaluation score, the tolerant might have been required should verbally demonstrate the level of pain, which might have been quell Similarly as none, mild, moderate, or severe, and numbered 0-3. Tolerant fulfillment level might have been archived on An scale starting with 0 should 10 (10, profoundly satisfied) contingent upon those stylish presence of the scar following those procedure, scar shade and pliability, easing for cohorted ache Also pruritus, and difficulties of the system. For respect to difficulties Previously, medicine about facial scars utilizing fat grafting, resorption from claiming fat graft. occurred in six cases. All complicated cases had no associated medical disorders. Tables $(1-6)$. 
Table (1) Results regarding vascularity of the scar.

\begin{tabular}{lcc}
\hline Vascularities & Before (n $(\boldsymbol{\%})$ & After $(\mathbf{n}(\boldsymbol{\%})$ \\
\hline 0 & $4(20)$. & $8(40)$. \\
$1 \mathrm{~N}$ & $10(50)$. & $10(50)$. \\
$2 \mathrm{~N}$ & $4(20)$. & $2(10)$ \\
$3 \mathrm{~N}$ & $2(10)$ & $0(0.0)$ \\
Total N & $20(100.0$ & $20(100.0)$ \\
\hline
\end{tabular}

Table (2) Results regarding scar pigmentation.

\begin{tabular}{lcc}
\hline Pigmentations & Before (n (\%) & After (n (\%) \\
\hline $\mathbf{0}$ & $8(40)$ & $16(80)$ \\
$\mathbf{1}$ & $0(0.0)$ & $0(0.0)$ \\
$\mathbf{2}$ & $3(15)$ & $2(10)$ \\
$\mathbf{3}$ & $9(45)$ & $2(10)$ \\
Total & $20(100.0$ & $20(100.0)$ \\
\hline
\end{tabular}

Table (3) Results regarding scar pliability.

\begin{tabular}{lcc}
\hline Pliability & Before $(\mathbf{n}(\boldsymbol{\%})$ & After $(\mathbf{n}(\boldsymbol{\%})$ \\
\hline $\mathbf{0}$ & $3(15)$ & $10(50.0)$ \\
$\mathbf{1}$ & $3(15)$ & $5(25)$ \\
$\mathbf{2}$ & $7(35)$ & $5(25)$ \\
$\mathbf{3}$ & $6(30)$ & $0(0.0)$ \\
$\mathbf{4}$ & $1(5)$ & $0(0.0)$ \\
$\mathbf{5}$ & $0(0.0)$ & $0(0.0)$ \\
Total & $20(100.0)$ & $20(100.0)$ \\
\hline
\end{tabular}

Table (4) Results regarding degree of pruritus.

\begin{tabular}{lcc}
\hline Pruritus & Before (n $(\boldsymbol{\%})$ & After $(\mathbf{n}(\boldsymbol{\%})$ \\
\hline $\mathbf{0}$ & $9(45)$ & $18(90)$ \\
$\mathbf{1}$ & $8(40)$ & $1(5)$ \\
$\mathbf{2}$ & $3(15)$ & $1(5)$ \\
$\mathbf{3}$ & $0(0.0)$ & $0(0.0)$ \\
Total & $20(100.0)$ & $20(100.0)$ \\
\hline
\end{tabular}

Table (5) Results as regarding degree of pain.

\begin{tabular}{lcc}
\hline Pain & Before $(\mathbf{n}(\boldsymbol{\%})$ & After $(\mathbf{n}(\boldsymbol{\%})$ \\
$\mathbf{0}$ & $13(65)$ & $18(90)$ \\
$\mathbf{1}$ & $5(25)$ & $2(10$ \\
$\mathbf{2}$ & $2(10)$ & $0(0)$ \\
$\mathbf{3}$ & $0(0.0)$ & $0(0.0)$ \\
Total & $20(100.0)$ & $20(100.0)$ \\
\hline
\end{tabular}

Table (6) Patient satisfaction with cosmetic appearance.

\begin{tabular}{lc}
\hline Before ( $\mathbf{n}(\%)$ & After \\
\hline $\mathbf{1 0}(\mathbf{5 0})$ & Excellent $(9-10)$ \\
$\mathbf{6}(\mathbf{3 0})$ & Good $(5-8)$ \\
$\mathbf{3}(\mathbf{1 5})$ & Fair $(3-4)$ \\
$\mathbf{1}(\mathbf{5})$ & Bad $(0-2)$ \\
\hline
\end{tabular}




\section{Discussion}

In this study, guys were influenced more than females - $11(55 \%)$ guys Furthermore $11(45 \%)$ females. Post traumatic scars spoken to $16(80 \%)$

situations. The mean period of patients might have been 29 a considerable length of time with $80 \%$ from claiming patients age-old underneath 40 years, which reflects the mastery from claiming youngsters in the study number. This Might make clarified Eventually Tom's perusing the mental trauma initiated by scars done junior patients compared with more seasoned ones.

The contributor webpage to $80 \%$ of the contemplated patients might have been the easier abdomen, this indicates that the sum of the hopefuls required abundant abdominal fat, which committed collecting simpler.

Roerich et al. , [11] compared harvests from the abdomen, thigh, flank, Also average knee Also all generated all the An statistically proportional number of feasible units. In contrast, in understanding for these findings, Guyuron Furthermore Majzoub utilized the same contributor locales The majority likely due to the same motivations simple approachability Also abundant fat [12].

Similarly as there is no clear correspondence between giver site area and life span of the embedded tissues, we don't Think as of that whatever contributor range will be superior. The collecting destinations ought further bolstering make undoubtedly open in the recumbent position, those position utilized for very nearly every last bit facial fat grafting methods. Therefore, the abdomen is the vast majority regularly utilized as contributor locales [13].

Throughout those fat grafting injection, it may be essential should discharge those adherences of the scar altogether its planes, Furthermore hence we break the hard sinewy tissue with the lipofilling cannula. In the starting of the infiltration, the scar offers helter skelter imperviousness to pasquinade the cannula, Anyway when the system progresses those fibrosis relaxes and fat infusion turns into simpler. In this study, An gruff cannula might have been utilized for scar discharge.

In the exhibit study, fat infusion might have been performed utilizing a $2 \mathrm{~mm}$ gruff cannula. Fat collecting might have been performed utilizing An 3 $\mathrm{mm}$ gruff multiperforated liposuction cannula, on get a lipoaspirate with little fat particles with provide a smooth birch infusion through those fine lipofilling cannula. If the fat particles need aid a really large, acceptably through those infusion cannula might a chance to be was troublesome Also disturbed infusion will follow, which might bring about an unequal lipofilling with unpredictable fat stores.
In this clinical study, autologous fat grafting finished preoperative desires. In regards the VSS, there might have been change in the vascularity and pliability of scars with change to scar pigmentation. There might have been also decrease in the level about agony Also tingling Concerning illustration evaluated by those self appraisal score. Tolerant fulfillment might have been attained On $76 \%$ from claiming instances.

In understanding with these results, Klinger et al. [14] reasoned that infusion of transformed alternately non - transformed autologous fat appears to be on a chance to be a guaranteeing and powerful restorative methodology should scars about diverse origin, and they stated that those dealt with regions recapture aspects comparable with ordinary skin What's more need aid clinically assessable, for not best stylish as well as practical effects. The dealt with skin gets All the more versatile What's more softer, permitting Indeed going on account of facial scars An gradual recuperation [15].

It might have been discovered that fat infusion might have been predominant On discouraged atrophic scars due to its filling character. In administration from claiming skin break out sequelae, those idiocy may be injected homogenously under those dermis will arrival those fibrosis As opposed to accomplishing a neighborhood volumizing impact. The part of the face enhances with fat grafting, which serves shroud those little cutaneous depressions brought about Toward skin break out.

Those consider seen An huge change for individual fulfillment following infusion $(79 \%)$ in examination with those preinjection state, and this is a great pointer of the impact from claiming fat infusion to bringing over An huge change in the scar. Jakson stated that tolerant fulfillment might have been $90 \%$, Despite those volume 'take' might have been not dependably addition in the observer's opinion, as recontouring included postradiation subcutaneous defects in the bring down limbs, which need aid not self-evident such as the face [16].

The exact component by which fat graft prompts tissue change is at present vague. These effects might a chance to be attained through MSCs instead of adipocyte inferred products, stromal development factors, hormones, tissue macrophage components, alternately every one these. Those correct part of undifferentiated units in the scar arrival methodology stays will be dead set. Probably, In those foundation of the tissue remodeling process, there will be nearby activity for cytokines, Growth factors, angiogenic factors, enzymes, Furthermore cell division segments held On lipoaspirates, prompting the shaping for new blood vessels for fibrotic tissue remodeling and another incendiary reaction [17]. 


\section{Conclusion}

This clinical study concluded that autologous fat grafting has a significant role in facial scar remodeling and provides a beneficial effect on facial scar tissue and scar-related conditions with not only esthetic but also functional results. Significant improvement in scar appearance, skin characteristics, and restoration of volume and threedimensional contour is reported. Associated pruritus and pain were also improved. In this study we used processed fat in half of cases and non processed in the other half and we found no difference in the outcome of facial scars as the regard self-assessment or the Vancouver scar scale so we consider them one group in result assessment.

\section{References}

[1] C. D. Marshall, M. S. Hu, T. Leavitt, L. A. Barnes, H. P. Lorenz, M. T. Longaker, "Cutaneous scarring: basic science, current treatments, and future directions," Adv. wound care; Vol.7(2), PP.29-45, 2018.

[2] S. Tejiram, S. L. Kavalukas, J. W. Shupp, A. Barbul, "Wound healing," in Wound healing biomaterials, Elsevier; Vol.3( 2), PP.3-39, 2016.

[3] M. Spiekman, J. A. van Dongen, J. C. Willemsen, D. L. Hoppe, B. van der Lei, M. C. Harmsen, "The power of fat and its adiposederived stromal cells: emerging concepts for fibrotic scar treatment," J. Tissue Eng. Regen. Med, Vol.11(11), PP.3220-3235, 2017.

[4] M. C. Robson, R. A. Barnett, I. O. W. Leitch, and P. G. Hayward, "Prevention treatment of postburn scars and contracture," World J. Surg, Vol.16(1), PP.87-96, 1992.

[5] B. S. Atiyeh, "Nonsurgical management of hypertrophic scars: evidence-based therapies, standard practices, and emerging methods," Aesthetic Plast. Surg; Vol.31(5), PP.468-492, 2007.

[6] W. J. Meyer III, J. A. J. Martyn, S. Wiechman, C. R. Thomas, L. Woodson, "Management of pain and other discomforts in burned patients," in Total burn care, Elsevier, Vol.5(3) PP.679$699,2018$.

[7] G. G. Gauglitz, H. C. Korting, T. Pavicic, T. Ruzicka, M. G. Jeschke, "Hypertrophic scarring and keloids: pathomechanisms and current and emerging treatment strategies," Mol. Med; Vol.17( 1-2), PP.113-125, 2011.

[8] V. L. Negenborn, J.-W. Groen, J. M. Smit, F. B. Niessen, M. G. Mullender, "The use of autologous fat grafting for treatment of scar tissue and scar-related conditions: a systematic review," Plast. Reconstr. Surg, Vol.137(1), PP.31-43, 2016.

[9] M. R. Kaufman , “Autologous fat transfer for facial recontouring: is there science behind the art?," Plast. Reconstr. Surg; Vol.119(7), PP.2287-2296, 2007.

[10]R. Fearmonti, J. Bond, D. Erdmann, H. Levinson, "A review of scar scales and scar measuring devices," Eplasty, Vol.10, 2010.

[11]D. Wan , "The differing adipocyte morphologies of deep versus superficial midfacial fat compartments: a cadaveric study," Plast. Reconstr. Surg, Vol.133, ( 5), PP.615622, 2014.

[12] J. Pak, J.-J. Chang, J. H. Lee, S. H. Lee, "Safety reporting on implantation of autologous adipose tissue-derived stem cells with platelet-rich plasma into human articular joints," BMC Musculoskelet. Disord; Vol.14(1), p. 337, 2013.

[13] R. A. Glasgold, M. J. Glasgold, S. M. Lam, "Complementary fat grafting," in Master Techniques in Facial Rejuvenation, Elsevier, Vol.14(7) PP.321-332,2018.

[14] M. Klinger ,"Autologous fat graft in scar treatment," J. Craniofac. Surg; Vol.24(5), PP.1610-1615, 2013.

[15]L. Huang , A. Burd, "An update review of stem cell applications in burns and wound care," Indian J. Plast. Surg, Vol.45(2), PP.229-236, 2012.

[16]S. Saunders , S. Longworth, Injection Techniques in Musculoskeletal Medicine EBook: A Practical Manual for Clinicians in Primary and Secondary Care. Elsevier Health Sciences, Vol.3(3), PP.34-45, 2018.

[17] A. Giordano, U. Galderisi, I. R. Marino, "From the laboratory bench to the patient's bedside: an update on clinical trials with mesenchymal stem cells," J. Cell. Physiol; Vol.211(1), PP.27-35, 2007. 